\title{
O valor da inovação em saúde
}

CAVACO DIAS, Casimiro.

\section{O valor da inovação: criar o futuro do sistema de saúde.}

Coimbra: Edições Almedina, 2015.

$\mid{ }^{1}$ José Canha Dias |

1 Imperial College London. Londres, Inglaterra (c.dias12@ic.ac.uk).

O debate político sobre as reformas de saúde tem gerado um espaço de diálogo, cada vez mais inclusivo, na criação de soluções inovadoras para melhorar a saúde da população. Contudo, esses debates integram poucas propostas para uma reforma holística do sistema de saúde. A promoção de cirurgias em ambulatório, o aumento da proporção de medicamentos genéricos ou o aumento do número de médicos de família correspondem a medidas isoladas, sem potencial para transformar o sistema de saúde.

O valor da inovação: criar o futuro do sistema de saúde é um dos primeiros livros em português sobre o impacto da inovação na transformação do setor da saúde, cobrindo uma lacuna importante. Ao longo da obra, Casimiro Cavaco Dias, economista da Organização Mundial da Saúde, avalia a capacidade de inovação do setor da saúde e seu impacto no desempenho do sistema.

O livro é fruto do projeto de investigação, cujo intuito foi compreender como iniciativas pontuais e isoladas dos hospitais mais inovadores se poderiam alargar a uma política pública. $\mathrm{O}$ autor centra-se nas questôes: como pode a inovação funcionar no setor da saúde? E o que esta mudança significa para o futuro da saúde? Na procura de respostas a estas questões, o autor ajuda-nos a descobrir por que alguns hospitais, e não outros, se tornam mais adaptativos, inovam e se transformam para melhorar seu desempenho. 
O Valor da Inovação proporciona-nos não só uma visão sistémica da inovação, mas também o ponto de partida para uma compreensão dinâmica do sistema de saúde. Por um lado, o estudo revela o processo de cuidados de saúde como o trajeto das pessoas através das organizações de saúde enquanto uma "cadeia de valor. Por outro, a cadeia de valor da inovação em saúde como um processo circular, continuamente revisto, face aos resultados e melhorias conseguidas. Nele são abordados os principais assuntos sobre a inovação em saúde ao longo de 11 capítulos estruturados em quatro partes. Incluindo os objetivos, as finalidades, os principais motores de inovação, a transformação de conhecimento, as novas competências, o papel estratégico da flexibilidade organizacional, o valor da inovação e, por último, as medidas para a promoção da inovação em saúde.

A primeira parte do livro inclui a introdução à inovação, tendo em conta as especificidades do setor da saúde, assim como a apresentação do modelo conceitual e dos métodos de investigação utilizado. O estudo adota métodos mistos para capturar a complexidade da inovação, incluindo questionário a 95 hospitais do setor público em Portugal, uma série de entrevistas aos hospitais mais inovadores e com maior desempenho, assim como a identificação das principais medidas de inovação por um painel de peritos em sistemas de saúde através da técnica de grupo nominal.

Ao longo da segunda parte da obra, revela-se a nova natureza da inovação em saúde. Assim, no quarto capítulo o autor analisa os principais objetivos da inovação no setor hospitalar. Para além da preocupação de melhorar o desempenho, os hospitais inovadores focam ainda na criação e utilização de novos conhecimentos. De fato, os hospitais destacam resultados menos tangíveis, como conhecimento, como fatores-chave não para assegurar a maximização do potencial das novas tecnologias e inovações organizações. O capítulo seguinte apresenta os novos motores da inovação no setor da saúde. Hoje, as novas tecnologias assumem papel importante como facilitador da inovação. A integração em redes de cooperação externa e novas formas de organização do trabalho são os principais motores da inovação no setor da saúde. No capítulo seis, destaca-se a capacidade de aprendizagem dos hospitais para se transformarem de forma contínua, assegurando maiores níveis de desempenho. Com novas formas de organização do trabalho, assentes sobretudo em redes de comunicação entre os departamentos e trabalho em equipe, esses hospitais 
criam e utilizam o conhecimento necessário à implementação de serviços mais ajustados às necessidades de seus utilizadores. Por outro lado, no capitulo seguinte, discutem-se as exigências que a inovação coôloca aos profissionais de saúde e gestores. Apesar da crescente especialização das profissões de saúde, as competências para inovação são sobretudo mais transversais, assegurando maior coordenação com o foco na pessoa e utilizador de serviços.

A terceira parte do livro olha sobretudo para o impacto da inovação no desempenho. O capítulo oito descreve o atual contexto como "hiper-turbulento", marcado pela atual crise econômica e financeira, onde é demasiado arriscado confiar apenas em abordagens tradicionais de gestão estratégica. Assim, a flexibilidade organizacional é uma opção estratégica cada vez mais importante para o setor da saúde. No capítulo seguinte, o autor analisa de forma crítica a relação entre a inovação e o desempenho. $\mathrm{O}$ estudo aponta que os hospitais inovadores e eficientes apresentam o dobro do nível de desempenho de outros hospitais, com a mesma capacidade de inovação. Este grupo de inovadores aposta, de forma estratégica, num número limitado de inovações com elevado potencial de transformação de toda a organização. Contudo, o valor da inovação vai para além do desempenho, para assegurar ainda ganhos em saúde, crescimento econômico e maior coesão social. No capítulo seguinte, um painel de peritos em sistemas de saúde identifica e prioriza as principais medidas para tornar o sistema de saúde o setor mais inovador da nossa sociedade. O reforço nos sistemas de informação e saúde é apontado como a medida para uma transformação estrutural visando melhorar o desempenho do sistema de saúde através da inovação.

A última parte do livro faz uma análise compreensiva da inovação como a solução para o sistema de saúde se tornar capaz de responder aos novos desafios que enfrenta. A inovação está no centro das estratégias de saúde não para conseguir mudanças incrementais, mas para mudar fundamentalmente a forma de pensar e desenhar os serviços de saúde do futuro. Os serviços de saúde necessitam de desenvolver novas competências no sentido de redefinir seu valor. À medida que o valor da inovação em saúde é compreendido como uma medida de resultados em saúde e de controle de custos, o sistema de saúde torna-se cada vez mais eficiente e inovador.

No último capítulo são apresentadas as implicações para os principais atores na transformação do sistema de saúde, com destaque para o próprio utilizador 
dos serviços. As principais implicações advêm da forma como os diferentes atores contribuem para o desenvolvimento da inovação. $\mathrm{O}$ autor aponta para a diversidade de formas de envolvimento na inovação. Tal acontece de cima para baixo, através de políticas nacionais de inovação, de baixo para cima, a partir da criatividade de soluções nos contextos locais, e de forma lateral, através da partilha de perspectivas entre diferentes setores da economia

As principais implicações advêm da forma como os diferentes atores contribuem para o desenvolvimento da inovação. Os resultados apontam três opções políticas para a promoção da inovação em saúde centradas sobretudo na amplitude e na diversidade das atuais redes de cooperação externa. Em primeiro lugar, a capacidade de inovação sai reforçada ao garantir que os profissionais de saúde são informados e capacitados nos diferentes níveis do sistema de saúde. Tal significa que os profissionais de saúde têm espaço suficiente para a criatividade e, simultaneamente controlam seu desempenho face aos objetivos operacionais previamente definidos e negociados. Segundo, à medida que os hospitais desenvolvem sistemas integrados de informação, será importante apoiar a troca de informação e a gestão do conhecimento no setor da saúde. Terceiro, a estrutura política deve apoiar uma participação ampla e dinâmica dos principais parceiros no desenvolvimento de inovação através de sistemas de incentivos. Nesse contexto, os hospitais, outros serviços de saúde, universidades e utilizadores de serviços têm a oportunidade de moldar as políticas e práticas para acelerar a inovação e a transformação do sistema de saúde.

O valor da inovação é de leitura obrigatória para os profissionais de saúde, os decisores políticos, os inovadores e todos os que se interessam no futuro da saúde. Talvez estas ideias possam estimular a discussão em torno de soluções robustas para a sustentabilidade do sistema de saúde. 